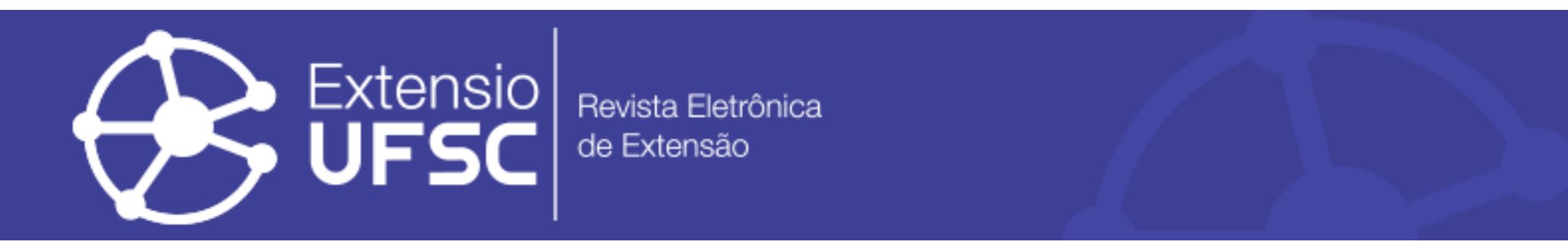

\title{
PROJETO CHEIRO VERDE NO QUINTAL DA ESCOLA: ALFABETIZAÇÃO PARA E PELO MEIO AMBIENTE
}

\author{
Mariza Konradt de Campos \\ Universidade Federal de Santa Catarina \\ marizakc@gmail.com \\ Cristiane Seimetz Rodrigues \\ Universidade Federal de Santa Catarina \\ cris.seimetz@gmail.com \\ Maria Elza de Oliveira Lima \\ Universidade Federal de Santa Catarina \\ elzalima2003@yahoo.com.br
}

\section{Resumo}

O Projeto de Ensino, Pesquisa e Extensão intitulado "Cheiro Verde no Quintal da Escola" vem sendo desenvolvido no Colégio de Aplicação da UFSC desde 2013. Ainda em andamento, o Projeto preconiza um trabalho multi e transdisciplinar sobre questões ambientais, abordando a importância de modelos sustentáveis de plantio, alimentação saudável e proteção da natureza junto a estudantes da Educação Básica e demais interessados da comunidade universitária e sociedade em geral. Empregando horta, pomar e demais elementos do quintal da escola como uma espécie de laboratório vivo, o Projeto vem conscientizando estudantes e famílias sobre temáticas ambientais diversas e evidenciando os benefícios de um contato mais próximo à natureza. Como resultado, tem-se conseguido alfabetizar os participantes para o meio ambiente, fazendo-os disseminadores dos valores praticados no "Cheiro Verde", e pelo meio ambiente, levando-os a lerem e escreverem com autonomia já no primeiro ano do Ensino Fundamental.

Palavras-chave: Meio Ambiente. Educação Ambiental. Alfabetização.

\section{THE “CHEIRO VERDE NO QUINTAL DA ESCOLA” PROJECT: LITERACY FOR AND BYTHE ENVIRONMENT}

\begin{abstract}
Since 2013, the teaching, research and outreach project entitled "Cheiro Verde no Quintal da Escola" (literally: Smell of Green in the School Garden) has been developed at Colégio de Aplicação, a primary and secontry school linked to the Federeal University of Santa Catarina, Brazil. Still in progress, the Project advocates a multi- and transdisciplinary work on environmental issues, addressing the importance of sustainable models for planting, healthy eating, and protection of nature with primary students, the university community, and society in general. Using the school's vegetable garden, orchard and other spaces as a kind of living laboratory, the Project has made students and families aware of diverse environmental issues and has pointed out the benefits of a closer contact with nature. As a result, they have become environmentally literate and disseminators of the values they learn and practice in the Project for the environment's sake, which helps them read and write autonomously in the very first year of primary school.
\end{abstract}

Keywords: Environment. Environmental Education. Literacy.

\section{PROYECTO CHEIRO VERDE NO QUINTAL DA ESCOLA: ALFABETIZACIÓN PARA Y POR EL MEDIO AMBIENTE}

Resumen

El Proyecto de Enseñanza, Pesquisa y Extensión intitulado "Cheiro Verde no Quintal da Escola" viene siendo desarrollado en el Colégio de Aplicação de la UFSC desde 2013. Aún en marcha, el Proyecto preconiza un trabajo multi y transdiciplinario sobre cuestiones ambientales, abordando la importancia de modelos sostenibles de plantío, alimentación saludable y protección de la naturaleza junto a estudiantes de la Educación Básica y demás interesados de la comunidad universitaria y sociedad en general. Empleando huerta, pomar y demás elementos del quintal de la escuela como una especie de laboratorio vivo, el Proyecto viene concienciando a estudiantes y familias sobre temáticas ambientales diversas y evidenciando los beneficios de un contacto más cercano a la naturaleza. Como resultado, se ha conseguido alfabetizar los participantes para el medio ambiente, haciéndolos diseminadores de los valores practicados en el "Cheiro Verde" y por el medio ambiente, llevándolos a leer y escribir con autonomía ya en el primer año de la Enseñanza Fundamental.

Palabras-clave: Medio Ambiente. Educación Ambiental. Alfabetización. 


\section{INTRODUÇÃO}

O presente artigo tem como objetivo apresentar o Projeto "Cheiro Verde no Quintal da Escola", descrevendo suas bases conceituais e as atividades desenvolvidas, bem como evidenciando seu papel na alfabetização das crianças que dele participam. Cabe assinalar que a alfabetização a que aqui se faz referência são duas, a saber: alfabetização para/sobre o meio ambiente e alfabetização pelo meio ambiente.

O Projeto "Cheiro Verde no Quintal da Escola", uma ampliação do Projeto "Um caminho diferente para aprender a ler e escrever", é desenvolvido no Colégio de Aplicação/UFSC desde 2013 e vem crescendo significativamente a cada ano. Envolvendo professores e bolsistas, o Cheiro Verde atende no período curricular os alunos do $1^{\circ}$ Ano A e dos $6^{\circ} \mathrm{s}$ anos do Ensino Fundamental. No período extracurricular, o Projeto é aberto a toda comunidade escolar, alunos de outras escolas da grande Florianópolis, graduandos e demais interessados. Estabeleceu-se parcerias com outras instituições e com professores de outros centros da UFSC. Desse modo, o projeto aqui apresentado se caracteriza como de Ensino, Pesquisa e Extensão.

Caracteriza-se como um projeto de Ensino, uma vez que as atividades desenvolvidas no período curricular estabelecem uma parceria com professores das diferentes disciplinas que já integram a proposta por meio de uma abordagem transdisciplinar. Envolve a pesquisa quando se aplicam questionários no início das atividades, para delinear a implementação da proposta, e ao final, para avaliar os resultados das ações. Envolve também pesquisas em busca de informações relacionadas à questões ambientais, sistemas de plantio, plantas, animais, entre tantas outras pautas relacionadas ao meio ambiente, as quais são socializadas por meio de publicações, participação em eventos externos, na Mostra Pedagógica do Colégio e na Semana de Ensino, Pesquisa e Extensão da Universidade Federal de Santa Catarina.

Caracteriza-se como projeto de Extensão, pois no período extracurricular, além de atender a toda comunidade escolar, o projeto atende outras escolas da grande Florianópolis, que vêm visitar a horta e conhecer as demais atividades do projeto (como compostagem e minhocário) e ainda atende turmas da graduação de diversos cursos da UFSC, as quais participam de oficinas e vêm buscar subsídios para implantar hortas escolares em outras instituições. Consolida-se como projeto de extensão, pois trabalha-se em parceria com a comunidade indígena da Escola Wherá Tupã Poty Djá, da Aldeia M’Biguaçu, com a qual se estabelece troca de sementes e mudas de plantas nativas e medicinais, bem como troca cultural sobre o trabalho com a natureza. Neste ano de 2018, iniciou-se parceria com a Universidad Central "Marta Abreu" de 
Las Villas, em Santa Clara, Cuba, e com a ONG "Pro Naturaleza - Rosa Elena Simeón", de Sagua la Grande, também em Cuba. Parceria essa que se constitui em trocas de informações sobre questões ambientais entre os alunos do projeto e alunos atendidos por essas instituições por meio de correspondências eletrônicas, cartas, troca de materiais no intuito de organizar futuras publicações. É preciso destacar que o Projeto conta com parceiros que, de diversas formas, viabilizam a realização do trabalho, como a equipe da Pró-Reitoria de Extensão PROEX/UFSC, da Pró-Reitoria de Graduação - DIP/PROGRAD/UFSC, da Biblioteca Universitária e da Prefeitura da UFSC. Há, ainda, parceiros de outros setores da sociedade envolvidos, como os integrantes do Programa Municipal de Agricultura Urbana - PMAU - de Florianópolis, que engloba a Secretaria de Saúde; Fundação Municipal do Meio Ambiente FLORAM; Superintendência de Pesca e Agricultura; Autarquia de Melhoramentos da Capital COMCAP, a qual já é parceira desde a criação do projeto; Empresa de Pesquisa Agropecuária e Extensão Rural de Santa Catarina - EPAGRI - e o Sesc Cacupé.

No que diz respeito ao Ensino, Pesquisa e Extensão, o eixo norteador da proposta é o desejo de promover diálogos e reflexões concernentes ao Meio Ambiente, focalizando três aspectos: sustentabilidade, alimentação saudável e a interação do ser humano com a natureza. Seguindo essa perspectiva, as atividades curriculares e extracurriculares desenvolvidas em função do "Cheiro Verde" são conduzidas no sentido de levar seus participantes a perceberem que a horta e o pomar cultivado favorecem a preservação ecológica, assim como a troca entre sabedoria popular e conhecimento científico, o que possibilita uma formação culturalmente diversificada. Para além desses benefícios apontados, concorda-se com Gadotti (2003, p.62) sobre outras potencialidades implicadas no trabalho com a horta, o pomar, a natureza:

\footnotetext{
Um pequeno jardim, uma horta, um pedaço de terra, é um microcosmos de todo o mundo natural. Nele encontramos formas de vida, recursos de vida, processos de vida. A partir dele podemos reconceitualizar nosso currículo escolar. Ao construí-lo e cultivá-lo, podemos aprender muitas coisas. As crianças o encaram como fonte de tantos mistérios. Ele nos ensina os valores da emocionalidade com a Terra: a vida, a morte, a sobrevivência, os valores da paciência, da perseverança, da criatividade, da adaptação, da transformação, da renovação.
}

A citação acima, que traduz o espírito do trabalho desenvolvido no "Cheiro Verde", também se coaduna com o que se espera de uma atividade projetada de acordo com a Lei da Educação Ambiental (lei n 9.795/99), que em seu primeiro artigo define educação ambiental como “ [...] processos por meio dos quais o indivíduo e a coletividade constroem valores sociais, conhecimentos, habilidades, atitudes e competências voltadas para a conservação do meio ambiente, bem de uso comum do povo, essencial à sadia qualidade de vida e sua 
Projeto Cheiro Verde no Quintal da Escola: alfabetização para e pelo meio ambiente

sustentabilidade". Assim, o trabalho de conscientização, sensibilização e alfabetização ambiental com a atual e as futuras gerações é a saída para o problema da finitude de recursos do planeta, bem como um caminho para o ensino da leitura e da escrita em contextos significativos e reais de uso da língua, tal qual como se pretende evidenciar a seguir.

\section{ALFABETIZAÇÃo PARA O MEIO AMBIENTE E PELO MEIO AMBIENTE}

\section{CONCEPÇÃO}

Uma vez que a Constituição Federal de 1988, em seu Art. 225, \ $1^{\circ}$, inciso VI, assegura o direito de todos ao meio ambiente ecologicamente equilibrado, bem de uso comum do povo e essencial à sadia qualidade de vida, atribuindo ao Estado o dever de "promover a educação ambiental em todos os níveis de ensino e a conscientização pública para a preservação do meio ambiente", subjaz a proposta do Projeto "Cheiro Verde no Quintal da Escola” a compreensão de que alfabetizar para/sobre o meio ambiente é munir as pessoas de conhecimentos essenciais à preservação da natureza e seus preciosos recursos. Processo de aprendizagem pelo qual todos e todas deveriam passar na atualidade, posto o quadro geral de dilapidação ao qual o planeta vem sendo submetido (CAPRA, 2003). Iniciar esse processo de ensino-aprendizagem já pelas crianças, na escola e fora da escola, tem a potencialidade de ser mais efetivo, porque elas se encontram em uma fase de desenvolvimento em que estão mais abertas a novos conhecimentos e em que os hábitos podem ser (re)educados.

Além disso, preparar as crianças para o bom trato do meio que as cerca as transforma em multiplicadoras desse conhecimento na medida em que elas o levam para casa e passam a esperar de sua família práticas mais condizentes com os valores que estão aprendendo. Este Projeto entende que é urgente compartilhar conhecimentos sobre os cuidados com a natureza para que a construção de um mundo mais humano, ambientalmente responsável e com valores elevados seja possível (CAPRA, 2003; GADOTTI, 2003).

Entre os saberes que o Projeto procura cultivar, estão os conceitos de agrofloresta, agricultura sintrópica e agroecologia. Praticam-se, ainda, os princípios da ecologia, de reutilização, reciclagem e compostagem, utilizando materiais descartáveis para fazer, por exemplo, vasos de plantas e resíduos orgânicos para a compostagem. Trabalham-se também os conceitos de alimentação saudável e preparo de alimentos nas oficinas culinárias.

No que concerne ao conceito de agrofloresta, procura-se demonstrar aos participantes do projeto os benefícios de se explorar a terra de modo sustentável, ou seja, combinando, “ [...] de maneira simultânea ou em sequência, a produção de cultivos agrícolas com plantações de árvores 
frutíferas ou florestais e/ou animais, utilizando a mesma unidade de terra e aplicando técnicas de manejo que são compatíveis com as práticas culturais da população local” (KING; CHANDLER, 1978). Trata-se, portanto, de um modelo de plantio que procura emular o que ocorre em uma floresta natural. A fim de adaptar essa prática ao espaço do quintal da escola, é que o projeto passa a explorar o conceito de agricultura sintrópica, a qual preconiza a integração da produção de alimentos à dinâmica de regeneração natural de florestas. Em se tratando de uma horta urbana, a concretização desse ideal se manifesta por meio da técnica de consórcio de plantas, em que se procura aproveitar tanto quanto possível recursos como solo, água e sol. É por essa razão que nos canteiros do quintal da escola do Colégio de Aplicação é possível encontrar hortaliças, árvores frutíferas, árvores florais, temperos, plantas medicinais e flores diversas.
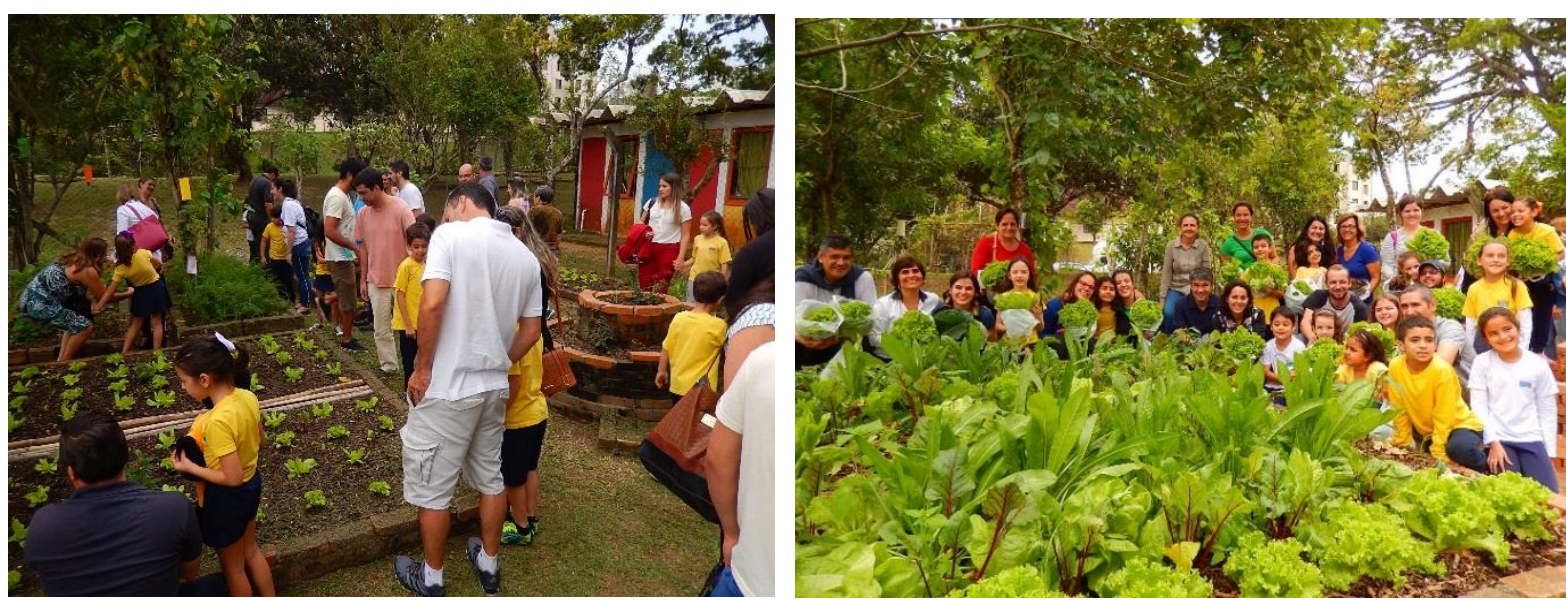

Figura 1: Presença da comunidade escolar para prestigiar o canteiro de hortaliças pós-plantio e colheita. Fonte: retirada pelas autoras.

Ainda no esforço de sensibilizar e educar estudantes, suas famílias e demais participantes sobre a degradação ambiental que os modelos tradicionais de agricultura implicam, os produtos produzidos no "Cheiro Verde" são cultivados de forma natural, isto é, sem o uso de agrotóxicos e adubos químicos solúveis. Por isto o interesse do Projeto pela compostagem e criação de um minhocário. A produção da horta é distribuída para os participantes do projeto, utilizada para a merenda, atendendo assim todos os estudantes da escola, e o excedente é doado. Por intermédio de todos esses conceitos, a proposta de educação ambiental aqui apresentada, tem reiterado, ano a ano, que a horta é um exemplar de como o solo é um organismo vivo e que o que se faz com ele é o que se recebe em troca. 
Projeto Cheiro Verde no Quintal da Escola: alfabetização para e pelo meio ambiente

\section{ATIVIDADES DESENVOLVIDAS}

O Projeto "Cheiro Verde no Quintal da Escola" teve início em 2013, com a instalação de canteiros para o plantio de hortaliças. A partir de 2014, adotou-se o conceito de agrofloresta, levando à incorporação de árvores frutíferas junto aos canteiros de hortaliças. $\mathrm{Na}$ classe de alfabetização do $1^{\circ}$ ano $A$, todo ano a professora Mariza trabalha com uma mascote de sala (um animalzinho de pelúcia) o qual é sempre o grande incentivador do projeto a ser desenvolvido.

Sob essa perspectiva, em 2014 a professora elegeu a tartaruga como a mascote da classe que desencadearia tanto a proposta de alfabetização ecológica quanto linguística daquele ano. Nomeado de Tamu, a mascote foi o objeto lúdico que permitiu explorar questões ambientais como aquecimento global, poluição e suas consequências para o ecossistema, uma vez que dependendo da temperatura nascem mais fêmeas do que machos e isso afeta a sobrevivência da espécie. A introdução da mascote é feita sempre de uma forma contextualizada e o mais real possível. Assim, o Tamu veio do Projeto TAMAR de Aracajú e foi apresentado às crianças, juntamente com fotos e um vídeo gravado pela Rejane, bióloga do TAMAR de Aracaju. A mascote chega com o discurso de que veio para o colégio para aprender a ler e escrever juntamente com os colegas, e também ensinar muitas coisas sobre a natureza.

A presença do novo amigo estimulou pesquisas em sala de aula sobre a vida das tartarugas marinhas, seu habitat, bem como saídas de campo para aprender mais sobre como proteger a tartaruga marinha e o seu meio ambiente.
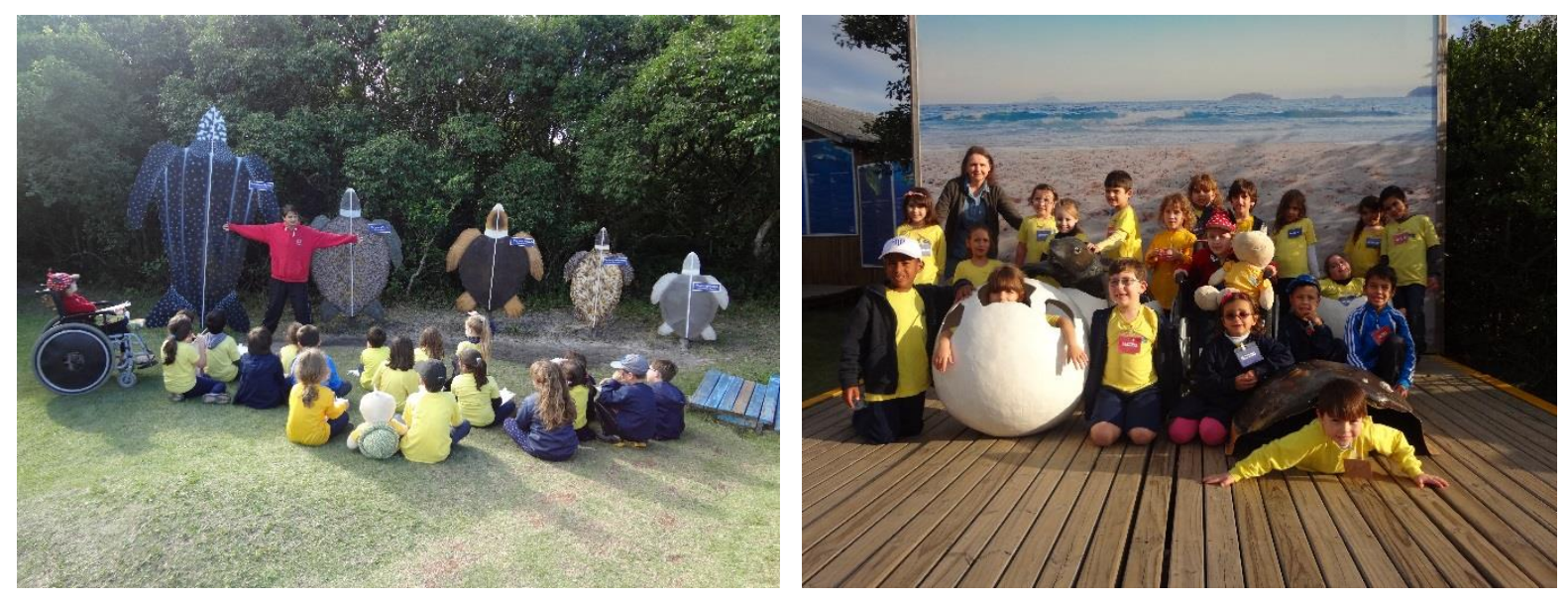

Figura 2: visita das crianças ao Projeto TAMAR de Florianópolis.

Fonte: registrada pelas autoras

Além da busca de mais informações sobre as tartarugas, o projeto também levou seus participantes a conhecerem mais sobre a diversidade marinha visitando o museu Oceanográfico do Complexo Ambiental Cyro Gevaerd - Zoológico da SANTUR, em Balneário Camboriú. 
Projeto Cheiro Verde no Quintal da Escola: alfabetização para e pelo meio ambiente

Após todas as pesquisas, registros e discussões realizadas sobre o tema das tartarugas marinhas e o aquecimento global, as crianças escreveram um livro, responsabilizando-se, com o auxílio da professora, a organizar as informações e conhecimentos obtidos durante a execução da proposta, bem como ilustraram a obra - tarefa em que receberam a ajuda da professora e artista plástica Karin Rosskamp.
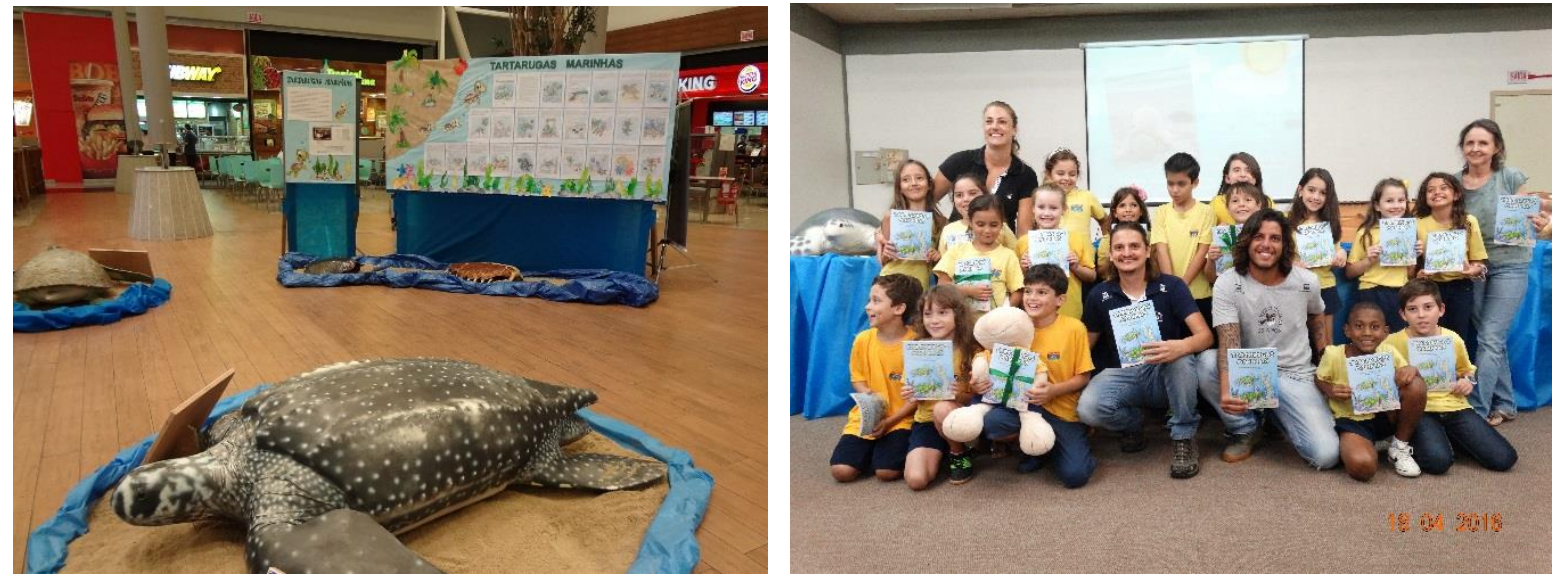

Figura 3: livro produzido pelas crianças exposto em forma de mural no Continente Park Shopping e lançamento do livro já em formato brochura no auditório do CA.

Fonte: registrada pelas autoras.

Inicialmente o livro foi divulgado em forma de mural na Exposição Tartarugas Marinhas no Continente Park Shopping e na sede do TAMAR em Florianópolis. Posteriormente o livro foi editado em parceria com a Biblioteca Universitária da UFSC e o TAMAR, passando a ser distribuído gratuitamente para todo o Brasil e exterior pelo próprio TAMAR. Outra ação muito impactante para os participantes do projeto que resultou da parceria com o TAMAR foi a produção de um filme usando a técnica do stopmotion.
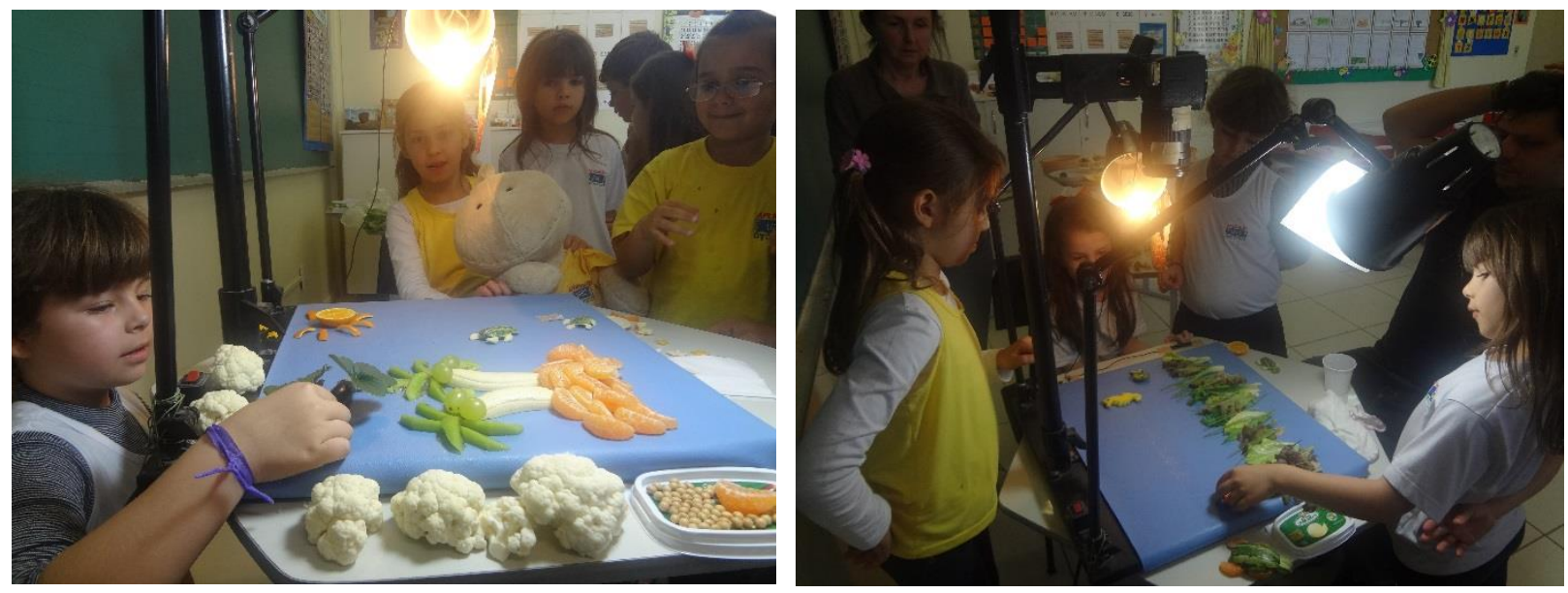

Figura 4: alunos do $1^{\circ}$ ano A produzindo o filme "Tamu e seus amigos: navegue nesta aventura".

Fonte: registrado pelas autoras. 
Com a codireção do artista Diego de los Campos, que auxiliou na gravação e edição do filme, foram utilizados elementos do quintal da escola, cultivados pelos estudantes ao longo do ano, como frutas, legumes e vegetais, para representar a história. A animação intitulada "Tamu e seus amigos: navegue nesta aventura" foi selecionada para o festival de cinema ECOCINE e exibido no PARATY ECO FESTIVAL, em Campinas, na UNICAMP, e em São Paulo. O filme ainda foi classificado para o FAM - $19^{\circ}$ Florianópolis Audiovisual Mercosul, em Florianópolis, e está disponível na página do TAMAR, no link: http://www.tamar.org.br/noticia1.php?cod=613. Assim, o livro e a produção do filme foram o produto de todo um ano de aprendizagens sobre a situação das tartarugas marinhas, ameaçadas pelo avanço da poluição nos mares, pela degradação ambiental que leva ao aquecimento global, e sobre a importância de preservar o meio ambiente para garantir a manutenção da diversidade biológica.

Como o "Cheiro Verde" assume o compromisso de se reinventar a cada ano, além das atividades envolvendo plantio, explora-se uma temática relacionada a questões ambientais. Em 2015, a água foi o tema explorado. Sob o slogan "A água que você não vê, mas consome”, desenvolveu-se a conscientização sobre a economia de água com atitudes simples no dia a dia, como fechar a torneira ao escovar os dentes e diminuir o tempo de banho. Trabalhou-se, ainda, com o conceito de pegada hídrica, o qual explora o volume de água usado para produzir os alimentos e outros produtos industrializados, o que nos ajuda a entender como nossas escolhas de produção e consumo afetam os recursos naturais (DA SILVA et al., 2013). Nesse ano, a mascote que balizou as atividades com a turma de alfabetização foi um golfinho, o Dolfi.

Em 2016, escolheu-se um macaco-prego, o Catu, como mascote, pois no CA há muitos saguis, animais não nativos dessa região. A partir deles, foi que se deu início à discussão sobre habitat natural e as consequências do desiquilíbrio ecológico para a sobrevivência de diversas espécies. Além disso, com os surtos de dengue, chikungunya e zika instalados em diversos locais pelo Brasil, os participantes do Projeto também enfrentaram o desafio de buscar informações sobre formas de combater os mosquitos ou, ainda, afastá-los usando elementos da própria natureza. Descobriram que, além da crotalária, uma planta que atrai libélulas, grandes predadoras dos mosquitos, existem outras plantas que podem auxiliar a afastar os mosquitos, agindo como repelentes naturais. Pesquisaram, assistiram a documentários, vídeos, leram, registraram e fizeram um canteiro com essas plantas. Para registrar o conhecimento construído, escreveram o livro "Plantas que repelem mosquitos". Todo o trabalho foi divulgado em diversos meios de comunicação e na Semana de Ensino, Pesquisa e Extensão da universidade (SEPEX).

Já no ano de 2017, os temas catalisadores para o processo de descoberta dos conhecimentos relativos ao meio ambiente foram a implementação de um canteiro de plantas 
medicinais de acordo com a prática chinesa do Relógio do Corpo Humano ${ }^{1}$ e a observação e estudo de abelhas nativas ou abelhas-sem-ferrão que se instalaram no muro do quintal da escola.

A proposta do canteiro de plantas medicinais seguiu a metodologia de trabalho que se caracteriza pela construção de uma horta em forma de relógio.
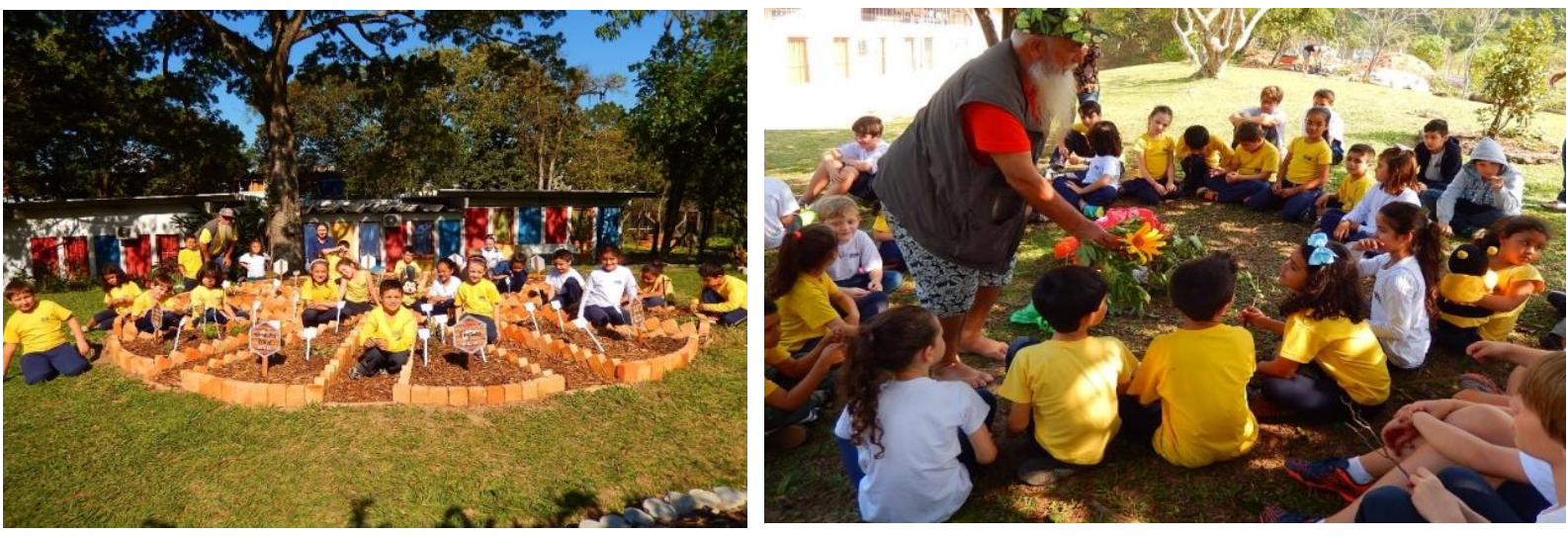

Figura 5: Estudantes do primeiro ano e dos sextos anos fazendo plantio no canteiro medicinal e aula ao ar livre sobre plantas medicinais e como usá-las.

Fonte: Retirada pelas autoras.

$\mathrm{Na}$ idealização do relógio medicinal do corpo humano, seleção das plantas medicinais e o estudo acerca delas, contou-se com a colaboração do professor Alésio dos Passos Santos. Conhecido como "mago das plantas", atua como ambientalista, cultivador e colecionador de plantas medicinais. Ele ministrou para o primeiro ano A e os sextos anos, no quintal da escola, aulas sobre várias plantas e como cada uma poderia ser preparada para ajudar a combater ou mesmo prevenir doenças. Para esse trabalho, contou-se ainda com a consultoria e colaboração do Dr. César Paulo Simionato, coordenador do Horto Medicinal do Hospital Universitário da UFSC. Os conhecimentos formais trazidos por essas parcerias foram complementados com a sabedoria popular, a qual foi investigada pelos estudantes do primeiro ano que realizaram entrevistas com seus avós a respeito de chás em geral e plantas medicinais.

A partir da proposta do Relógio do Corpo Humano e as Plantas Medicinais foi possível desenvolver atividades multidisciplinares envolvendo diversas áreas. Além do conhecimento sobre as plantas medicinais, em que se explorou a identificação e utilização segura, plantio e reprodução de mudas, degustação de chás, exploraram-se ainda os órgãos do corpo humano e suas funções. Oportunizou-se também reflexões sobre alimentação saudável e segurança alimentar, cuidados básicos com a saúde, educação e preservação ambiental. Para enfatizar a importância da alimentação saudável e a questão da segurança alimentar, recorreu-se a atividades

\footnotetext{
${ }^{1} \mathrm{Na}$ medicina chinesa, esse método de trabalho segue o princípio de que "cada planta tem um horário específico para atuar em determinado órgão do nosso corpo, horário este que o órgão está em melhor funcionamento” (VIEIRA, EPIFANIO, SODRÉ, 2017, p. 09).
} 
de degustação de frutas e a oficinas de culinária empregando alimentos saudáveis e receitas mais naturais.
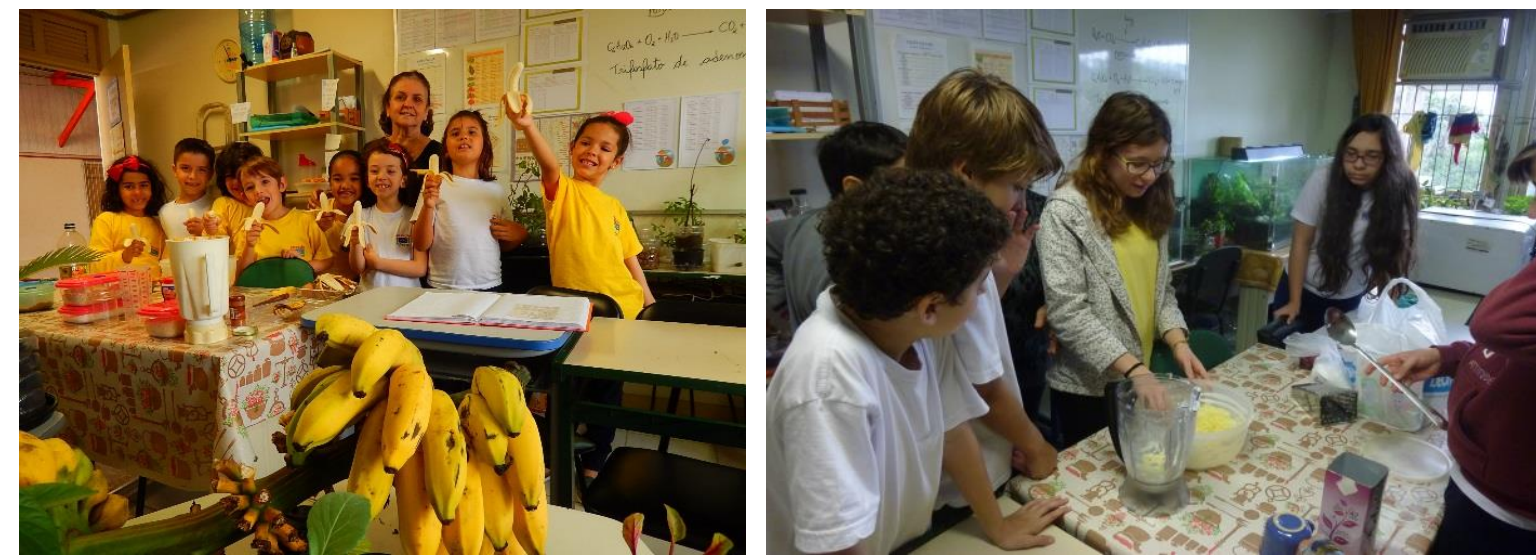

Figura 6: Estudantes do primeiro ano e dos sextos anos em uma oficina de culinária saudável, preparando bolo de banana com a professora Maria Elza.

Fonte: retirada pelas autoras.

Em relação à proposta de estudo de abelhas nativas ou abelhas-sem-ferrão, explorou-se a relação direta e interdependente entre as abelhas nativas e as plantas, já que estas dependem da polinização para a reprodução e aquelas dependem das plantas para obterem alimento. Os participantes foram levados ainda a refletir sobre o risco da diminuição da população das abelhas, pois isso implica em perda de biodiversidade de plantas, o que repercute na cadeia alimentar de todos os animais, inclusive na do ser humano. $\mathrm{Na}$ turma de primeiro ano, o trabalho foi norteado pela inserção da mascote Bely, uma abelha mandaçaia de pelúcia. A mascote foi empregada como estímulo para a turma explorar o ecossistema e questões como preservação do meio ambiente, habitat, cadeia alimentar, extinção de espécies, o respeito às diferenças, etc. Também a afetividade estabelecida com a Bely foi crucial para deixar as crianças seguras e interessadas em observar as colônias de abelhas jataís que vivem no quintal do CA. Por meio dessa observação, fez-se a ponte para o estudo do ciclo de vida das abelhas, como cuidar delas, o que levou à ação de florir a escola para garantir fonte de alimentos para elas. Para a realização do estudo das abelhas, o Cheiro Verde contou com a parceria do Laboratório de Abelhas Nativas da UFSC - LANUFSC - e com a Empresa de Pesquisa Agropecuária e Extensão Rural de Santa Catarina - EPAGRI.

Diante da importância das abelhas para a manutenção da biodiversidade, produção de alimentos no mundo e para o desenvolvimento de um mundo sustentável e, ainda, considerando que as mesmas estão ameaçadas de extinção, optou-se em 2018 por continuar as discussões sobre as abelhas tendo como mascote do primeiro ano A, uma abelha jataí, a Mel. Começou-se uma campanha pela escola divulgando informações sobre a importância das abelhas e pretende-se investir na criação do Recanto das Abelhas-Sem-Ferrão, espaço no quintal da escola onde serão 
Projeto Cheiro Verde no Quintal da Escola: alfabetização para e pelo meio ambiente

instaladas colmeias de abelhas nativas no intuito de tornar nossa escola amiga das abelhas. Paralelamente ao trabalho sobre as abelhas, os sextos anos vêm realizando estudos sobre plantas comestíveis não convencionais. Todo esse trabalho também está sendo socializado com as crianças de Cuba atendidas pelas instituições parceiras de lá por meio de correspondências eletrônicas e cartas, entre os estudantes daqui e de lá, relatando sobre como as questões ambientais são tratadas em suas respectivas escolas e países.

Como se pode observar da exposição feita até aqui, a participação das crianças do primeiro ano A no Projeto, as quais têm entre seis e sete anos de idade, se dá de forma lúdica e aprendem a ler e escrever num contexto de educação ambiental. Isso é alfabetizar pelo meio ambiente, visto que as propostas de trabalho do "Cheiro Verde" permitem lançar mão desse trabalho de sensibilização e conscientização a respeito das questões ambientais para educar os estudantes a lerem e escreverem com autonomia. Nesse sentido, desde o princípio, parte-se da concepção de que aprender a ler não deve ser um fim em si mesmo. Deve, antes, ser um meio. O meio pelo qual é possível perseguir e alcançar outras aprendizagens, usando, para tanto, a leitura. Assim, as atividades de pesquisa, registro, relato, discussão e exposição motivadas pelo Projeto junto às crianças desempenham papel central em seu desenvolvimento também na linguagem escrita. O mesmo se dá com os estudantes dos sextos anos, que ampliam seus conhecimentos curriculares em Ciências e repertório de gêneros textuais ao entrarem em contato com diferentes materiais de estudo durante suas pesquisas. A atividade constante de registro e, finalmente, a organização desses conhecimentos em livros também nos sextos anos possibilita a reflexão contextualizada sobre a linguagem escrita nas aulas de Português.

\section{OS FRUTOS COLHIDOS ATÉ AQUI}

Com a condução deste Projeto desde 2013, são várias as realizações alcançadas. Em primeiro lugar, o resultado mais evidente àqueles que participam do projeto é a questão da alfabetização ambiental e linguística de modo lúdico, incentivando desde cedo à pesquisa, reflexão e troca de saberes. Outro aspecto relevante é a inserção das famílias dos estudantes, que apoiam o projeto doando sementes, mudas e materiais para a montagem dos canteiros e do viveiro de mudas mantido pelo "Cheiro Verde". Atitudes como essas são um reflexo de que, em seu período de existência, o Projeto vem mostrando à comunidade escolar seu potencial de impactar positivamente os hábitos alimentares, de higiene e de relação com a natureza dos estudantes do primeiro ano A e dos sextos anos. 
Todavia, há ainda muitos desafios a superar no que tange à sensibilização dos estudantes para uma vida mais natural, principalmente os estudantes dos sextos anos, que já passaram, na maioria dos casos, toda a infância afastados de práticas relacionadas ao Meio Ambiente e demonstram, assim, dificuldades para entender a horta como a expansão da sala de aula; como espaço de aprendizado, de transmissão de conhecimento. No início das atividades de degustação e de culinária saudável, muitos tendem a rejeitar frutas como melão, manga, mamão, atendo-se a frutas como banana e maçã, evidenciando, portanto, pouca diversidade alimentar. Algo semelhante acontece nas oficinas culinárias, em que eles pedem que as receitas levem mais açúcar ou mais sal, demonstrando um paladar já altamente habituado aos produtos processados da indústria alimentícia. Após alguns meses de trabalho, é possível perceber que, mesmo entre os mais resistentes, há aqueles que começam a mudar de postura e a valorizar as atividades conduzidas pelo "Cheiro Verde". É possível que o fato de o trabalho com a horta ser menos integrado ao currículo dos sextos anos em comparação ao do primeiro ano, acabe gerando esse estranhamento inicial sobre por que e para que ir para o quintal, mexer na terra, plantar, regar, colher, observar. Quanto a isso, tem-se, ano a ano, feito esforços para envolver mais disciplinas e professores dos sextos anos na execução do Projeto. Atualmente, colaboram com o "Cheiro Verde" as disciplinas de Ciências e Português.

De positivo, pode-se relatar ainda que, nesses cinco anos de projeto, foram elaborados pelos participantes atendidos pelo "Cheiro Verde", livros que reúnem o conhecimento construído coletivamente. Exemplo disso são os livros lançados pelo $1^{\circ}$ ano A sobre minhocas (2013), sobre tartarugas marinhas (2014), sobre golfinhos (2015), sobre plantas que repelem mosquitos (2016) e sobre plantas medicinais (2017) que foram e são empregados como recurso didático no Colégio de Aplicação e que ficam à disposição das escolas que visitam o Projeto. Os sextos anos também produziram livros sobre essas temáticas; em especial sobre plantas, abordando as medicinais, os temperos e as flores. Entre os livros citados, foram editados e integram o acervo da Biblioteca Central da UFSC (BU) e do Colégio, o Minhocas e Tartarugas Marinhas. Está no prelo para ser publicado pela BU o livro Relógio do Corpo Humano. Esses três livros fazem parte da Série Quintal da Escola, criada pela BU para publicação das produções do Cheiro Verde.

Os materiais editados são distribuídos para escolas, nas bases do TAMAR e também são enviados para a comunidade indígena da Escola Wherá Tupã Poty Djá, da Aldeia M’Biguaçu, e para os novos parceiros na Universidad Central "Marta Abreu” de Las Villas, em Santa Clara, bem como para ONG "Pro Naturaleza - Rosa Elena Simeón”, de Sagua la Grande, ambas em 
Cuba. Parceria essa que se estabeleceu após eles terem recebido do TAMAR os materiais sobre tartarugas marinhas produzidos pelos alunos do Projeto "Cheiro Verde no Quintal da Escola".

Os frutos do trabalho realizado pelo Projeto são divulgados no Bio na Escola ${ }^{2}$, na SEPEX, na Mostra Pedagógica do Colégio de Aplicação, entrevistas a rádio Universitária, canais de televisão, portal do G1 Santa Catarina, G1 Globo, site do Colégio, Revista Gestão Universitária, site do TAMAR, exposições, minicursos e no catálogo de extensão da PROEXUFSC.

Por fim, em reconhecimento a todo o trabalho desempenhado no Projeto "Cheiro Verde no Quintal da Escola”, em 2018 ele foi agraciado como um dos ganhadores do $2^{\circ}$ Prêmio Escoteiros do Brasil de Educação por sua perspectiva de ecoalfabetização, que alia a alfabetização das crianças à conscientização ambiental e alimentação saudável.

\section{CONSIDERAÇÕES FINAIS}

Com este artigo, pretendeu-se evidenciar que a educação ambiental é uma ferramenta para o enfretamento dos problemas ambientais na dimensão da educação, capaz de contribuir com mudanças e transformações sociais, como apregoa o Programa Nacional de Educação Ambiental - ProNEA (BRASIL, 2005). Ademais, é um poderoso instrumento, quando integrado ao currículo, na alfabetização dos estudantes. A educação acadêmica e a educação ambiental têm na horta e no pomar um laboratório vivo que possibilita o desenvolvimento de diversas atividades pedagógicas em educação ambiental e alimentar, unindo teoria e prática de forma significativa e contextualizada, auxiliando no processo de ensino-aprendizagem e estreitando relações através da promoção do trabalho coletivo e cooperado entre os agentes sociais envolvidos em busca de uma cultura de sustentabilidade.

Espera-se com o Projeto "Cheiro Verde no Quintal da Escola" e o relato acerca dele aqui exposto levar ao entendimento de que é muito importante que cada um faça alguma coisa para preservar a natureza e garantir também às próximas gerações o direito de sobreviver e usufruir dos mesmos recursos de que dispomos hoje; afinal, tudo o que utilizamos e consumimos é retirado dela. É um contínuo desafio, frente a uma sociedade cada vez mais afastada da natureza, conscientizar de que os recursos são finitos, de que a ciência e a tecnologia não poderão salvar a humanidade em um cenário de escassez de recursos naturais. Daí a necessidade premente de educar a população, as novas gerações, para uma sensibilidade diferenciada em relação às

\footnotetext{
2 Trata-se de um Subprojeto de Ciências Biológicas do Programa Institucional de Bolsas de Iniciação à Docência (Bio PIBID - UFSC) em que os trabalhos desenvolvidos pelos bolsistas junto às escolas onde atuam são apresentados nessas respectivas escolas para conhecimento de toda a comunidade escolar (estudantes, professores, técnicos e famílias).
} 
Projeto Cheiro Verde no Quintal da Escola: alfabetização para e pelo meio ambiente

questões da natureza, de fazê-las entender que o consumo tem um preço que não é apenas monetário, mas também ambiental e social.

\section{REFERÊNCIAS}

BRASIL. Constituição Federal do Brasil: estabelece os princípios da política nacional do meio ambiente. 1988.

BRASIL. Lei n. 9795 - 27 de abril de 1999. Dispõe sobre a educação ambiental. Política Nacional de Educação Ambiental. Brasília, 1999.

BRASIL. Programa nacional de educação ambiental - ProNEA / Ministério do Meio Ambiente, Diretoria de Educação Ambiental; Ministério da Educação. Coordenação Geral de Educação Ambiental. - 3. ed - Brasília: Ministério do Meio Ambiente, 2005.

CAPRA, F. Alfabetização ecológica: o desafio para a educação do século 21. In: TRIGUEIRO, A. (Coord.). Meio ambiente no século 21: 21 especialistas falam da questão ambiental nas suas áreas de conhecimento. 3. ed. Rio de Janeiro: Sextante, 2003. p. 18-33.

DA SILVA, V.P.R et al. Uma medida de sustentabilidade ambiental: Pegada hídrica. Revista Brasileira de Engenharia Agricola e Ambiental-Agriambi, v. 17, n. 1, 2013.

GADOTTI, M. Boniteza de um sonho: ensinar-e-aprender com sentido. Novo Hamburgo: Feevale, 2003.

KING, K.F.; CHANDLER, N.T. The wasted lands: The program of work of the International Council for Research in Agro forestry (ICRAF). Nairobi, Kenya, 1978.

VIEIRA, N. E. M.; EPIFANIO, S. S.; SODRÉ, L. V. Relógio do corpo humano. Revista Educar Mais, n. 1, 2017.

Recebido em: 06/11/2018

Aceito em: 26/11/2018 